\title{
Impact of COVID-19 pandemic on safe abortion and family planning services at a tertiary care women's hospital in Nepal
}

\author{
Sangeeta Kaushal Mishra ${ }^{1 *}$, T. Geetha Rana ${ }^{1}$, Shree Prasad Adhikary ${ }^{1}$, \\ Sandesh Paudel ${ }^{1}$, Prabhu Sah $^{2}$
}

\begin{abstract}
${ }^{1}$ Department of Obstetrics and Gynecology, Paropakar Maternity and Womens Hospital, Kathmandu, Nepal
${ }^{2}$ Ilam District Hospital, Ilam, Nepal
\end{abstract}

Received: 11 April 2021

Revised: 08 May 2021

Accepted: 10 May 2021

\section{*Correspondence:}

Dr. Sangeeta Kaushal Mishra,

E-mail: drsangeetamishra@gmail.com

Copyright: () the author(s), publisher and licensee Medip Academy. This is an open-access article distributed under the terms of the Creative Commons Attribution Non-Commercial License, which permits unrestricted non-commercial use, distribution, and reproduction in any medium, provided the original work is properly cited.

\begin{abstract}
Background: The COVID-19pandemic emerged as a major public health crisis, which has affected all dimensions of the health care system. Sexual and reproductive health services were severely affected, leading to a decrease in access and service utilization, affecting the overall health of women.

Methods: A two-year comparative study, before and during the COVID-19 pandemic, on safe abortion services and family planning, was conducted at Paropakar maternity and women's hospital to assess the impact of COVID-19 on service utilization.

Results: Safe abortion services were decreased by $34.4 \%$, and family planning services by $39 \%$, in 2020 as compared to the previous year. Uptake of long-acting reversible contraceptives and permanent methods was most affected. Utilization of services was affected markedly during lockdown, and showed a persistent decline, even after the lockdown was lifted.

Conclusions: The COVID-19 pandemic has seriously affected safe abortion and family planning services in Nepal due to lockdown, travel restriction, home isolation, resource reallocation, health facilities serving only emergencies and confusing messages about COVID-19 control. The decline in these services will create additional demand and pressure on the health care system, resulting from unplanned pregnancies and unsafe abortions. Health care staffs should be reoriented about the essential nature of safe abortion and family planning services during emergencies, and the implications of service disruption, on society and the country. Pragmatic and gender sensitive changes to national policies should be made, to ensure that women's health is safeguarded, and safe abortion and family planning included as essential health care services during emergencies.
\end{abstract}

Keywords: Safe abortion, Contraception, Family planning, COVID-19, Sexual and reproductive health, Nepal

\section{INTRODUCTION}

The COVID-19 pandemic has emerged as a major public health care crisis. Governments all over the world have quickly adapted and responded, to interrupt the virus transmission chain, and in providing care to those infected. Nepal announced nationwide lockdown on 23
March; in response many health institutions curtailed their regular services, providing emergency care only.

Previous experiences of all major epidemics since 2003 have shown a serious negative impact on maternal, reproductive and child health services. Resource diversion for outbreak management, has contributed to a rise in negative outcomes for regular programs, including 
increased maternal mortality, unsafe pregnancies and unsafe abortions. ${ }^{1}$ Reports from the 2014-2015 Ebola epidemic suggest, that the shutdown of routine services resulted in more maternal and child mortality and morbidity than the outbreak itself. ${ }^{2}$

Nepal has seen a dramatic decrease in maternal mortality rate (MMR) over the last two decades, declining from 901 per 100,000 live births in 1990 to 258 per 100,000 live births in 2016. ${ }^{3}$ This decline has been largely attributed to the legalization of abortion, availability of safe abortion and family planning services in Nepal. Unsafe abortion is one of the most preventable causes of maternal mortality worldwide. ${ }^{4}$ Safe abortion services are very crucial as they are time sensitive and women may resort to unsafe measures, in absence of these services. Limited access to family planning services can lead to increase in unwanted pregnancy, leading to psychological stress and an increased possibility of resorting to unsafe means of termination, if safer options are unavailable.

In the face of COVID-19 infection, with national lockdown and surge in COVID cases, it is plausible that routine safe abortion services were affected, leading to increased risk to women health. This study aims to determine the effect of COVID-19 on safe abortion and family planning services, at a tertiary referral women's hospital in Nepal.

\section{METHODS}

This is a comparative research study of data for two years (2019 and 2020), before and during the COVID pandemic, on safe abortion services and family planning. This study was conducted at Paropakar maternity and women's hospital (PMWH), Kathmandu, Nepal. PMWH is a tertiary teaching and referral hospital situated in the capital of Nepal, the biggest and only hospital dedicated to reproductive health. Safe abortion and family planning services are one of the major services provided in this hospital apart than regular maternity and gynecological care. More than $50 \%$ of the total deliveries in Kathmandu valley are conducted at this hospital, and $26 \%$ of total abortion services in Kathmandu. Hospital continued its regular services along with safe abortion and family planning facilities during COVID-19 pandemic.

The abortion and family planning unit registry at PMWH, were used to collect data for two years a presented in the tables below. The Pre-COVID period is taken as being from 1 January 2019 to 31 December 2020, while the COVID pandemic period is taken from 1 January 2020 to 31 December 2020. The first case of COVID 19 was reported in Nepal on 24 January followed by a nationwide lockdown from 23 March $2020 .^{5}$ We compared the yearly data as a whole, to get an aggregate and also compared monthly data, so that seasonal variations could be taken into account. We also analyzed quarterly data for uptake of services in the same year to account for pre lockdown, lockdown and post lockdown service utilization and compared it to the previous year.

\section{Inclusion and exclusion criteria}

Criteria for inclusion and exclusion in current study were; all women attending abortion and family planning unit for services, and who fall under legal framework of service provision of abortion were included. Women more than 22 weeks were excluded.

\section{Data analysis}

Microsoft Excel version 2016 was used to analyze the collected data. Comparisons of data during these periods are reported as percentage differences.

\section{RESULTS}

Data for two years (2019 and 2020) were collected and compared. The demographic characteristics of women attending abortion and family planning clinics is presented in Table 1 and Table 2 . The majority of women seeking abortions were from 21-40 years with parity 2; $84 \%$ had education only up to higher secondary and were mostly from upper caste and janjati groups.

Similarly most family planning users were also from the 21 to 40 years age group with parity $2.67 \%$ of these women had education upto higher secondary and were again, mostly from upper caste groups and janjati. Safe abortion services in the year 2020,were decreased by $34.4 \%$ as compared to the year 2019 (Table 3)

First trimester services were severely affected much more so than second trimester abortion services. (38\% vs. $2.4 \%$ ) There was almost no difference in the total number of clients seeking second trimester abortion services. (Table 3)

Overall, 39\% decrease in the utilization of family planning services was noted during the year of pandemic, as compared to the pre-COVID year. There was a significant decrease in utilization of all the methods of family planning; however, the greatest reduction was seen in the use of long-acting reversible contraceptives (LARC) and permanent methods. (Table 4)

The lockdown in Nepal, which started on 24 March, continued for four months, ending on 21 July 2020. The data for safe abortion and family planning services was also analyzed for three periods, pre- lockdown, lockdown and post lockdown and compared to the previous year's data for the same months. The differences in service utilization were striking as compared to the previous year.

Service utilization for both safe abortion as well as family planning services, showed an increasing trend in the pre lockdown period in 2020. However, during the lockdown 
period, the services were decreased by more than 50 percent as compared to the previous year. The data after lockdown also shows a decline of more than $40 \%$ in first trimester abortion and family planning service utilization, with a nominal increase in second trimester service utilization in 2020 as compared to 2019. (Table 5)

\section{DISCUSSION}

The COVID-19 pandemic is impacting severely on the delivery of sexual and reproductive healthcare across the world. The lockdown has affected reproductive health services with a negative impact on women's health overall; however, women from disadvantaged groups face even greater challenges. ${ }^{6}$

Table 1: Demography of comprehensive abortion care users at PMWH.

\begin{tabular}{|lllll|}
\hline Parameters & 2019 & \multicolumn{2}{l}{2020} \\
\hline & $\mathrm{N}$ & $\%$ & $\mathrm{~N}$ & $\%$ \\
\hline Age (years) & & & & \\
\hline$\leq 20$ & 172 & 12 & 155 & 17 \\
\hline $21-30$ & 583 & 42 & 407 & 44 \\
\hline $31-40$ & 592 & 42 & 305 & 33 \\
\hline $41-49$ & 49 & 4 & 49 & 5 \\
\hline Total & 1396 & & 916 & \\
\hline Education level & & & & \\
\hline 0-5 Primary & 392 & 28 & 233 & 25 \\
\hline $\begin{array}{l}\text { 6-8 Lower } \\
\text { secondary }\end{array}$ & 142 & 10 & 89 & 10 \\
\hline 9-10 Secondary & 345 & 25 & 237 & 26 \\
\hline Higher secondary & 292 & 21 & 200 & 22 \\
\hline Bachelor's & 164 & 12 & 105 & 11 \\
\hline Master's & 61 & 4 & 52 & 6 \\
\hline Total & 1396 & & 916 & \\
\hline Parity & & & & \\
\hline Nullipara & 176 & 13 & 215 & 24 \\
\hline Para 1 & 343 & 24 & 208 & 23 \\
\hline Para 2 & 696 & 50 & 244 & 27 \\
\hline Para 3 and above & 181 & 13 & 249 & 26 \\
\hline Total & 1396 & & 916 & \\
\hline Caste/ ethnicity & & & & \\
\hline Dalit & 74 & 5 & 35 & 4 \\
\hline Janjati & 638 & 46 & 407 & 44 \\
\hline Madheshi & 86 & 6 & 39 & 4 \\
\hline Muslim & 35 & 3 & 32 & 3 \\
\hline $\begin{array}{l}\text { Brahmin } \\
\text { upper caste) }\end{array}$ & 563 & 40 & 403 & 44 \\
\hline Total & 1396 & & 916 & \\
\hline & & & & \\
\hline & & \\
\hline
\end{tabular}

According to International Planned Parenthood Federation (IPPF), the South Asia region has seen the largest number of closure of clinics and service outlets. They have been forced to cut sexual and reproductive health services as a result of COVID-19 restrictions, and also limitation in availability of key commodities and supplies. ${ }^{7}$

Table 2: Demography of family planning users at PMWH.

\begin{tabular}{|c|c|c|c|c|}
\hline \multirow[t]{2}{*}{ Parameters } & \multicolumn{2}{|l|}{2019} & \multicolumn{2}{|l|}{2020} \\
\hline & $\mathrm{N}$ & $\%$ & $\mathrm{~N}$ & $\%$ \\
\hline \multicolumn{5}{|l|}{ Age (years) } \\
\hline$\leq 20$ & 446 & 10 & 215 & 7 \\
\hline $21-30$ & 2444 & 48 & 1040 & 33 \\
\hline $31-40$ & 1229 & 25 & 1335 & 43 \\
\hline $41-49$ & 891 & 17 & 536 & 17 \\
\hline Total & 5110 & & 3126 & \\
\hline \multicolumn{5}{|l|}{ Education level } \\
\hline 0-5 Primary & 448 & 9 & 244 & 8 \\
\hline $\begin{array}{l}\text { 6-8 Lower } \\
\text { secondary }\end{array}$ & 136 & 3 & 386 & 12 \\
\hline 9-10 Secondary & 1113 & 22 & 576 & 18 \\
\hline Higher secondary & 1894 & 37 & 687 & 22 \\
\hline Bachelor's & 902 & 18 & 830 & 27 \\
\hline Master's & 617 & 12 & 403 & 13 \\
\hline Total & 5110 & & 3126 & \\
\hline \multicolumn{5}{|l|}{ Parity } \\
\hline Nullipara & 220 & 4 & 106 & 3 \\
\hline Para 1 & 1620 & 32 & 1162 & 37 \\
\hline Para 2 & 2830 & 55 & 1655 & 53 \\
\hline Para 3 and above & 440 & 9 & 203 & 6 \\
\hline Total & 5110 & & 3126 & \\
\hline \multicolumn{5}{|l|}{ Caste/ ethnicity } \\
\hline Dalit & 953 & 19 & 359 & 11 \\
\hline Janjati & 1364 & 27 & 995 & 32 \\
\hline Madheshi & 826 & 16 & 531 & 17 \\
\hline Muslim & 282 & 6 & 112 & 4 \\
\hline $\begin{array}{l}\text { Brahmin } \\
\text { (upper caste) }\end{array}$ & 1685 & 33 & 1129 & 36 \\
\hline Total & 5110 & & 3126 & \\
\hline
\end{tabular}

Current study shows a significant reduction in abortion and family planning services. The overall utilization of safe abortion services decreased by $34 \%$. It is interesting to note the large reduction in first trimester $(38 \%)$ compared to the much smaller fall in second trimester abortions (2.35\%) (Table 3). This data suggests that women who planned early pregnancy abortions had to wait till lockdown was lifted to avail of services (Table 
3). First trimester abortions are considered easy, safe, require less expertise and are available easily in all registered centers. The services for second trimester abortions are available in a limited number of hospitals in Nepal, as they need higher degree of expertise, skill and a more advanced clinical set up. This data clearly shows that there was a shift in percentage of clients seeking first trimester abortion to second trimester abortion, as compared to the previous year. Restricted access of safe abortion increases the likelihood of women resorting to unsafe measures due to lack of access and expertise. There may be rise in unwanted pregnancies with psychological and economic consequences for women and their families.

Table 3: Safe abortion services, first and second trimester.

\begin{tabular}{|llll|}
\hline $\begin{array}{l}\text { Year } \\
\text { (January to } \\
\text { December) }\end{array}$ & $\begin{array}{l}\text { First } \\
\text { trimester }\end{array}$ & $\begin{array}{l}\text { Second } \\
\text { trimester }\end{array}$ & Total \\
\hline $\mathbf{2 0 1 9}$ & 1263 & 133 & 1396 \\
\hline $\mathbf{2 0 2 0}$ & 786 & 130 & 916 \\
\hline
\end{tabular}

Table 4: Family planning services.

\begin{tabular}{|llll|}
\hline Method Type & $\begin{array}{l}\text { Year } \\
\text { 2019 }\end{array}$ & $\begin{array}{l}\text { Year } \\
\mathbf{2 0 2 0}\end{array}$ & \% Reduction \\
\hline Condoms & 2800 & 1512 & 46 \\
\hline COC & 311 & 291 & 6.43 \\
\hline Injectables & 412 & 336 & 18.45 \\
\hline Implants & 1327 & 836 & 37 \\
\hline IUCD & 223 & 133 & 40.4 \\
\hline $\begin{array}{l}\text { Bilateral tube } \\
\text { ligation (interval) }\end{array}$ & 37 & 18 & 51.4 \\
\hline Total & 5110 & 3126 & 38.9 \\
\hline
\end{tabular}

Family planning services decreased by 39\%. The reduction in use of long term reversible contraceptive (LARC) and permanent methods is significantly greater than short term contraceptive methods (Table 4). LARC is recommended as a primary option for contraception to reduce unwanted pregnancy due to the high level of effectiveness, safety and lesser chances of failure. ${ }^{8}$ The reduction in the use of long term and permanent contraception is an indirect indicator of the increased likelihood of unwanted pregnancies and its future implications.

Long term reversible contraceptive (LARC) methods require women to go the health facility to seek services, as well as needing trained human resources. While travel restriction and forced home isolation, are seen as the cause of reduced uptake of these services, the lack of clarity among the public as well as service providers, about which services were expected to be available without compromise during the lockdown, is possibly a major contributor to the decline in these services. Historically, contraception and safe abortion care have been described as 'elective' or ' on request' and therefore universally not considered essential, or in some cases even legitimate healthcare. ${ }^{9}$ This narration of abortion being non-essential and an elective procedure, has negatively affected sexual and reproductive health of women for long.

A comparison of the data pre lockdown, lockdown and post lockdown in pre- pandemic (2019) and during the pandemic (2020), shows dangerous trends. While service utilization showed an increasing trend before lockdown, there was a drastic decrease of more than $50 \%$ during the lockdown, which can be explained by multiple factors described above. However even after the lockdown was lifted, service utilization was slow to pick up. Service utilization of first trimester abortion and family planning services, decreased to more than $40 \%$ as compared to the previous year; however, there was a minimal increase of $4.6 \%$ in seeking for second trimester abortion services (Table 5). It appears women as well as their family members, were still confused and wary of visiting the hospital, leading to continued slowing in utilization. A very important lesson learnt from this data is that once there is disruption in services due to any reason, it is difficult to attain normalcy and get the clients back into the system. There is evidence from previous epidemics mainly Ebola that service utilization had not recovered to prior levels, even after six months. ${ }^{10}$ This indirectly implies that service disruption has a sustained effect and can be very detrimental for women's health.

According to a recent study based on Guttmacher Institutes Adding it up 2019 study on SRH provision in 132 low and middle income countries, it was estimated that $10 \%$ proportional decline in short-acting reversible contraceptive use in Nepal, due to decrease in access to services, would result in 131,700 women with unmet need for modern contraception and an estimated 19,000 extra unintended pregnancies over a twelve months period. Similarly, the impact of $10 \%$ shift in abortions from safe to unsafe, assuming no change in the overall number of abortions or live births, estimated 14,500 unsafe abortions in place of safe abortions. ${ }^{11,12}$

The decrease in maternal mortality in Nepal has been directly linked to legalization of abortion and expansion of safe abortion services all over the country. ${ }^{13}$ The decline in services during emergencies such as the COVID-19 pandemic, makes women vulnerable to undergo unsafe abortion with inadequate post abortion care, which can lead to serious complications such as post-abortion sepsis, hemorrhage, perforation, genital trauma and maternal death. These complications are higher, when unsafe abortion is performed in the later months of pregnancy. ${ }^{13,14}$ Similarly women carrying unplanned pregnancy are more prone to delay or not seek antenatal care, which is associated with twice the risk of severe maternal and perinatal morbidity, including premature birth, intrauterine growth restriction, intrauterine fetal death, postpartum hemorrhage, 
eclampsia and placental abruption, when compared to women with planned and adequate antenatal care. ${ }^{15}$

The sharp decline in service utilization at PMWH, implies that there is an increase in unintended pregnancies as well as unsafe abortions. Though we do not have any direct data about unsafe abortions during the period of the lockdown, it would be interesting to conduct a community-based study in this regard.

\section{Summary}

The COVID-19 pandemic has seriously affected safe abortion and family planning services in Nepal. National lockdown, travel restriction, home isolation, resource reallocation, health facilities serving only emergencies, and confusing messages and understanding, during the COVID-19 pandemic, are possible explanations for the decline in service utilization. However, it must be understood, that the potential large increase in unplanned pregnancies and unsafe abortions, will create additional demand and pressure on an already burdened health care system, in low resource countries such as Nepal. Health care staffs should be reoriented during emergencies about the essential nature of safe abortion and family planning services and implications of service disruption on society and the country. This calls for pragmatic and gender sensitive changes to national policies to ensure that women's health is safeguarded and safe abortion and family planning are included as essential health care services during any emergency, such as the current COVID-19 pandemic, and in all contingency plans.

Table 5: A comparison of safe abortion and family planning service utilization- before lockdown, during and after lockdown, compared with the previous year.

\begin{tabular}{|c|c|c|c|c|c|c|c|c|c|}
\hline \multirow[t]{2}{*}{ Services } & \multicolumn{2}{|c|}{$\begin{array}{l}\text { Pre-lockdown } \\
4 \text { months }\end{array}$} & \multirow[t]{2}{*}{$\begin{array}{l}\% \\
\text { increase/ } \\
\text { decrease }\end{array}$} & \multicolumn{2}{|c|}{$\begin{array}{l}\text { lockdown } \\
4 \text { months }\end{array}$} & \multirow[t]{2}{*}{$\begin{array}{l}\% \\
\text { increase/ } \\
\text { decrease }\end{array}$} & \multicolumn{2}{|c|}{$\begin{array}{l}\text { Post lockdown } \\
4 \text { months }\end{array}$} & \multirow[t]{2}{*}{$\begin{array}{l}\% \\
\text { increase/ } \\
\text { decrease }\end{array}$} \\
\hline & 2019 & 2020 & & 2019 & 2020 & & 2019 & 2020 & \\
\hline $\begin{array}{l}\text { First trimester } \\
\text { abortion services }\end{array}$ & 382 & 398 & 4.2 & 473 & 207 & -56.2 & 339 & 189 & -44.3 \\
\hline $\begin{array}{l}\text { Second trimester } \\
\text { abortion services }\end{array}$ & 35 & 37 & 5.7 & 51 & 25 & -51 & 44 & 46 & 4.6 \\
\hline Family planning & 1440 & 1576 & 9.4 & 1557 & 587 & -62.3 & 1413 & 767 & -45.7 \\
\hline
\end{tabular}

Local government can play a key role to help identify the needs of women and to increase access to reproductive health services, working directly with communities, to ensure distribution and collection points for family planning commodities and medical abortion at the health units of local government (Palika), through involvement of female community health volunteers (FCHV) and local health staff. Virtual and self-care models of safe abortions with community participation as well as a strong backup plan to manage complications should be rolled out, with an interrupted supply chain during this period.

\section{Limitations}

Limitations of current study were; study was based on the data from a single tertiary women's hospital, located in the capital of Nepal and thus the findings cannot be generalized to the rest of the country. It is advisable to analyze data from other hospitals to determine trends in utilization of these services, at other levels of the health system in the country.

\section{CONCLUSION}

The COVID-19 pandemic has seriously affected the access to safe abortion and family planning services in Nepal. While the reduction in Family planning service utilization was $39 \%$, SAS service utilization was reduced by $34.4 \%$ between 2019 and 2020, with a disproportionately greater impact on first trimester abortions. This implies that more women are resorting to unsafe abortion or having unwanted pregnancies, with resulting serious implications on women's health, and potentially increased maternal mortality and morbidity. The ministry of health and population, Nepal and its

developmental partners should take immediate actions to classify family planning and Safe Abortion services as a priority and essential services, to be continued during this pandemic. Reorientation of health care staff and female community health volunteers, use of telehealth (both audio and video), self-care models for use of medical abortion and family planning and upholding skilled service providers at facility seems obligatory. With the wake of a second wave of COVID infection, and rise in cases, integration of sexual and reproductive health as a part of the COVID-19 response plan is much needed, and failing to do so may threaten the achieved progress on maternal health in the millennium development goals, and reducing the likelihood of achieving the sustainable development goal targets for maternal mortality and sexual and reproductive health.

\section{Funding: No funding sources}


Conflict of interest: None declared

Ethical approval: The study was approved by the Institutional Ethics Committee

\section{REFERENCES}

1. Reproductive, maternal, newborn and adolescent health during pandemics. Available at: https://wcaro.unfpa.org/en/publications/reproductivematernal-newborn-and-adolescent-health-duringpandemics-lessons-learned. Accessed on 20 February 2021.

2. Elston JWT, Cartwright C, Petal N. The health impact of 2014-15 Ebola Outbreak. Public Health. 2017;143:60-70

3. Government of Nepal. Annual Report 2017/72(2014/2015) Kathmandu: Ministry of Health and Population, Department of Health services 2015. Available at: http://dohs.gov.np/wp-content/uploads/ 2016/06/Annual_Report_FY_2071_72.pdf. Accessed on 20 February 2021.

4. Preventing unsafe abortion. Available at: https://www.who.int/news-room/factsheet/detail/preventing-unsafe-abortion. Accessed on 20 February 2021.

5. Covid-19 Pandemic in Nepal-Wikipedia. Available at: https://en.wikipedia.org> wiki>COVID-19_pand emic_in_Nepal. Assessed on 15 February 2021.

6. Karkee R, Morgan A. Providing maternal health services during the Covid-19 pandemic in Nepal. Lancet Glob Health. 2020;8:1243-44.

7. COVID-19 pandemic cuts access to sexual and reproductive healthcare for women around the world. Available at: https://www.ippf.org/news/covid-19pandemic-cuts-access-sexual-and-reproductivehealthcare-women-around-world. Accessed on 20 February 2021.
8. Birgisson NE, Zhao Q, Secura GM, Madden T, Peripert JF. Preventing unintended pregnancy: the contraceptive choice project in review. Women Health. 2015;24(5):349-53

9. Bayefsky MJ, Watson KL. Abortion during Covid 19 pandemic-ensuring access to an essential health service. N Engl J Med. 2020;382:e47.

10. Ayadi AM, Sidibe AM. Ebola outbreak on reproductive health services in a rural district of Guinea: an ecological study. Transact Royal Soc Trop Med Hygiene. 2017;111(1):22-9

11. Sully EA. Adding it up: investing in sexual and reproductive health. Available at: http://www. guttmacher.org/report/adding-it-upinvesting-insexual-reproductive-health-2019. Assessed on 20 January 2021.

12. Assessed impact of the COVID-19 pandemic on sexual and reproductive health in Nepal. Nepal Health Res Counc. 2020;18(47):313-5.

13. Henderson JT, Puri M, Blum M, Harper CC, Rana A, Gurung $\mathrm{G}$, et al. Effects of abortion legalization in Nepal, 2001-2010. PLOS One. 2013;8(5):e64775.

14. World Health Factsheet, preventing unsafe abortion, 2020. Available at: https://www.who.int/newsroom/fact-sheets/detail/preventing-unsafe-abortion. Accessed on 25 March 2021.

15. Brown SS, Eisenberg L. The best intentions unintended pregnancy and the well-being of children and families. US: National Academies Press; 1995.

Cite this article as: Mishra SK, Rana TG, Adhikary SP, Paudel S, Sah P. Impact of COVID-19 pandemic on safe abortion and family planning services at a tertiary care women's hospital in Nepal. Int J Reprod Contracept Obstet Gynecol 2021;10:2453-8. 